\title{
Monoparentalidade, Pobreza e Resiliência: Entre as Crenças dos Profissionais e as Possibilidades da Convivência Familiar
}

\author{
Single-parenthood, Poverty and Resilience: The Professional's Beliefs \\ and the Possibilities of Family Life
}

\author{
Maria Angela Mattar Yunes*, Narjara Mendes Garcia \\ \& Beatriz de Mello Albuquerque \\ Fundação Universidade Federal do Rio Grande, Rio Grande, Brasil
}

\begin{abstract}
Resumo
O presente artigo apresenta um estudo comparativo entre as crenças de agentes comunitários de saúde sobre possibilidades de resiliência em famílias monoparentais e de baixa renda e as estratégias de enfrentamento das adversidades que emergem nas histórias de vida destas famílias. Tomou-se como base a noção de resiliência aplicada à Psicologia, que se refere aos processos que explicam a superação de adversidades. Foram entrevistados quatro agentes comunitários de saúde e quatro famílias monoparentais. As estratégias metodológicas foram: entrevistas semi-estruturadas, histórias de vida, entrevista reflexiva e a análise dos dados através da groundedtheory. Os resultados revelaram crenças pessimistas dos agentes comunitários sobre o funcionamento das famílias pobres, em contraposição aos fatores indicativos de resiliência constatados nas histórias de vida destas famílias. Os resultados sinalizam para a necessidade de transformar e adequar as percepções dos agentes sociais acerca de grupos que vivem situação de pobreza.

Palauras-chave. Resiliência; famílias monoparentais e de baixa renda; agentes comunitários de saúde; crenças sobre pobreza.

Abstract

This article presents a comparative study on the health community agent's beliefs about the possibilities of resilience in low-income single-parent families and the coping strategies of these families in adverse situations that emerge from their life stories. The notion of resilience as applied in Psychology was taken as reference, which refers to the processes that explains how people overcome adversities. Four health agents and four single parent families were interviewed. The methodological strategies to guide the data analysis were: open interviews, life stories, reflexive interviews and grounded-theory. The results showed that the community agents hold pessimist beliefs about the poor families functioning in opposition to the elements that indicate resilience in these families' life stories. The results point to the need of transforming and adjusting the social agent's perceptions on groups who live in poverty.

Keywords: Resilience, low-income single-parent families, health community agents, beliefs on poverty.
\end{abstract}

Em muitos países da Europa, nos Estados Unidos e no Canadá, a palavra resiliência é utilizada coloquialmente, seja no cotidiano de conversas informais ou para justificar, referir e direcionar programas políticos de ação social e educacional. No Brasil, sua expressão ainda demanda explicações, com exceção de poucos grupos de pessoas de algumas áreas de conhecimento específicas, como a Engenharia (resiliência/resistência de materiais) ou a Ecologia (resiliência de sistemas ambientais).

Resiliência é um conceito originário da Física e referese à capacidade de um material absorver energia sem sofrer deformação plástica ou permanente. Na Psicologia os

* Endereço para correspondência: Rua Vasco da Gama, 51 , Apto. 801, Porto Alegre, RS. Fone/ Fax: Oxx51 33125467. E-mail:yunes@vetorial.net

Artigo premiado em $1^{\circ}$ lugar na área das Ciências Humanas na III Mostra da Produção Universitária da Fundação Universidade Federal de Rio Grande, 2004

Agradecemos o apoio do CNPq sob a forma de bolsa PIBIC, conferida à segunda autora e financiamento através do Edital Ciências Humanas e Sociais de 2004 e Universal de 2005. estudos sobre o tema datam cerca de trinta anos. Alguns autores contemporâneos optam por definir resiliência referindo-se aos processos através dos quais as pessoas enfrentam e a superam crises e adversidades (Garcia \& Yunes, 2006; Masten, 2001; Walsh, 1996, 1998, 2003, 2005; Yunes \& Szymanski, 2001; Yunes, 2003, 2006a, 2006b, entre outros). Entretanto, a tônica dos estudos nacionais e internacionais ainda permanece com foco no indivíduo, ou melhor, na criança ou adolescente (Masten \& Garmezy, 1985; Rutter, 1985, 1993; Trombeta \& Guzzo, 2002; Werner \& Smith, 1992). Recentemente o fenômeno da resiliência foi desmistificado como um "ingrediente mágico" do dinamismo humano e reconhecido como comum e presente no desenvolvimento de qualquer indivíduo (Masten, 2001). Alguns estudiosos têm enfatizado a necessidade de cautela no uso "naturalizado" do termo (Martineau, 1999; Yunes, 2001b, 2003, 2006a, 2006b).

Tratar da resiliência em famílias significa focar e pesquisar os aspectos sadios e de sucesso do grupo familiar ao invés de destacar seus desajustes e falhas. Segundo 
Walsh (1996), "o foco da resiliência em família deve procurar identificar e implementar os processos chaves que possibilitam famílias, não só a lidar mais eficientemente com situações de crise ou estresse permanente, mas saírem fortalecidas das mesmas" (p. 263). Portanto, resiliência em famílias não se refere apenas a processos de adaptação e coping do grupo familiar, mas busca compreender as transformações "positivas" que decorrem do enfrentamento da situação estressora (Walsh, 2005). No Brasil e no exterior os pesquisadores da resiliência em famílias vêm divulgando com freqüência cada vez maior e mais intensa as suas discussões (Cecconello, 2003, De Antoni \& Koller, 2000, McCubbin, Thompson, Thompson \& Futrell, 1999, Walsh, 1998, 2003, Yunes, 2001b).

Em consonância com tais considerações é preciso chamar a atenção para estudos sobre famílias, especialmente para "famílias pobres", cujos aspectos "não-saudáveis" ou "deficitários" são frequentemente enfocados (Garcia \& Yunes, 2006; Yunes, 2001a; Yunes \& Szymanski, 2001, no prelo). Uma criança pobre "sintomática" ou um adolescente "com problemas na escola" logo dirigem o pensamento das pessoas - educadores ou não - para os possíveis "desajustes" de suas famílias. Compreender os mecanismos que "dirigem" estes pensamentos e crenças pessimistas é uma das preocupações deste estudo. Considera-se que o interesse pelo estudo da resiliência em famílias pode contribuir para reverter esse ciclo de raciocínio e trazer uma ênfase "salutogênica" (Antonovsky \& Sourani, 1988) e mais otimista para a compreensão do mundo familiar.

\section{Resiliência e Crenças sobre Pobreza}

Um estudo realizado sobre as crenças e a postura de trabalhadores sociais do extremo sul do RS, diante das famílias pobres, demonstrou que os mesmos descrevem estes grupos familiares como acomodados e submissos à situação de miséria (Yunes, 2001b). Os profissionais caracterizaram as famílias como "desestruturadas", pela sua configuração não-nuclear e pelas expressões de violência nas relações intrafamiliares apontadas como: abandono, negligência das crianças e incidência do uso de drogas por pelo menos um membro da família. A autora da investigação afirma que os profissionais acreditam na transgeracio-nalidade destas características, o que perpetua os mitos familiares de "acomodação" e "desestruturação". Por alguma razão, os profissionais entrevistados alegam que as famílias pobres sempre replicam (nunca corrigem) os scripts das gerações precedentes. Yunes (2001b) reforçou ainda que "não foram encontradas em pesquisas brasileiras, evidências científicas que comprovem a linearidade destas conclusões" (p. 83) que, todavia imperam no imaginário dos trabalhadores e provavelmente dirigem as suas práticas de atuação em saúde e educação junto às famílias. Em consonância com estas reflexões estão os resultados de um outro estudo realizado por uma pesquisadora norte americana que aponta críticas aos trabalhadores dos serviços de saúde mental por suas tendências em associar especialmente as famílias monoparentais de baixa renda aos cuidados parentais "negligentes", postura profissional que pode acabar "culpando a vítima" (Madanes, 1984).

Na realidade, pouco se sabe sobre os processos e dinâmica de funcionamento de famílias pobres, embora alguns estudos brasileiros demonstrem que estas famílias mostram-se muitas vezes, hábeis na tomada de decisões e na superação de grandes desafios, evidenciando uma unidade familiar e um sistema moral bastante fortalecido diante da proporção das circunstâncias desfavoráveis de suas vidas (Carvalho, 1995; Mello, 1995; Sarti, 1996; Szymanski, 1988). Sabe-se que as condições indignas e a precariedade das contingências econômicas e sociais que castigam a maioria das famílias brasileiras podem afetar de forma adversa o desenvolvimento de crianças, adolescentes e adultos. Entretanto, isso não pode ser considerado regra sem exceção, pois muitas vezes alguns grupos desenvolvem processos e mecanismos que garantem sua sobrevivência, não só física, mas dos valores de sua identidade cultural (Sonn \& Fisher, 1998). Assim, muitos grupos familiares que vivem situações de risco cumprem seu papel de proteção e cuidado com competência e tornamse o contexto essencial para o desenvolvimento saudável de seus membros e não são inevitavelmente "disfuncionais" (Lindblad-Goldberg, 1989; Yunes, 2001b).

Sendo assim, pesquisas sobre resiliência e famílias de baixa renda despertam interesse por possibilitar compreender os processos que permeiam o contexto familiar de grupos que enfrentam as dificuldades da pobreza. Estes processos não devem ser considerados pressupostos para uma definição "engessada" de resiliência em famílias, pois sabe-se que este fenômeno pode se apresentar sob diferentes prismas e possibilidades em cada contexto familiar. Pesquisas já realizadas com famílias pobres demonstram que o exercício da percepção da "alteridade" e da solidariedade, ou seja, colocar-se no lugar do outro e estar "aberto"/sem preconceitos ajuda a compreender as diversidades e são importantes elementos da dinâmica familiar que permitem que estas famílias afirmem que "vivem bem" (Sarti, 1996; Yunes, 2001b; Yunes \& Szymanski, no prelo). Nesse sentido, ressaltamos a importância de reconsiderar o reconhecimento de pobreza e miséria como fatores de risco universais (Luthar \& Zigler, 1991).

Ao investigar a questão da resiliência em grupos sociais pobres, este trabalho busca ampliar o espectro destas conclusões voltando a atenção para a identificação de fatores de proteção que garantem propostas de vida saudável, oportunidades de desenvolvimento integral e sentimentos de dignidade para as famílias menos favorecidas socialmente.

\section{Os Grupos Pesquisados: as Famílias Monoparentais em Situação de Pobreza e os Agentes Comunitários de Saúde}

As famílias monoparentais e de baixa renda - geralmente matrifocais, ou seja, chefiadas por mulheres -, constituem um grupo cada vez mais expressivo em nossa sociedade. Segundo dados do censo demográfico de 2000, realizado pelo Instituto Brasileiro de Geografia e Estatística (IBGE), aproximadamente $25 \%$ das famílias brasileiras são lidera- 
das por mulheres. Assim, parece importante que pesquisas científicas sejam elaboradas para investigar a vida destas famílias. Alguns cientistas chamam a atenção para o "modelo de déficit" e alegam que é preciso reconsiderar adjetivos atribuídos pejorativamente às famílias monoparentais, tais como: "desestruturadas", "desorganizadas", "desviantes", "instáveis" ou "desintegradas" (LindbladGoldberg, 1989, Szymanski, 1988, Yunes, 2001b). Na atual situação social e momento histórico é preciso remarcar que esta é apenas mais uma forma alternativa de família dentre tantas outras. Entretanto, é inegável que quando se trata de famílias de baixa renda, a monoparentalidade pode ser uma dificuldade a mais que sobrecarrega, em geral, a figura feminina. Isso sugere que as mulheres de classes de baixa renda e no papel de provedoras (Sarti, 1996) enfrentam uma somatória de problemas e mudanças que transcendem a questão da pobreza em si. Desta forma, é preciso relevar a importância de uma rede de apoio social efetiva que possa acolher indivíduos e grupos que enfrentam esse acúmulo de situações de risco psicossocial e ambiental. Para conhecer a inserção das famílias e suas relações/interações com os demais sistemas ecológicos de influência que definem o ecossistema familiar (Bronfenbrenner, 1979/1996) é necessário situar e conhecer mais profundamente os programas públicos de atendimento às famílias através do estudo da figura do agente comunitário de saúde.

Os agentes comunitários de saúde podem fazer parte de dois programas de saúde: o PACS - Programa de Agentes Comunitários de Saúde - criado e financiado pelo Governo Federal desde 1991 ou o PSF - Programa Saúde da Família - implantado em 1994 a partir do PACS (Ministério da Saúde, 2001).

No PACS, os agentes comunitários de saúde realizam um trabalho semelhante ao do PSF, com a diferença que os integrantes deste último constituem uma equipe multiprofissional que é composta no mínimo, por um médico, um enfermeiro e um auxiliar de enfermagem. Estes se propõem a estar em constante movimento de colaboração e suporte mútuo. Os integrantes do PACS atuam nas vilas, orientados por reuniões com os coordenadores e palestras realizadas esporadicamente por médicos, enfermeiros e demais profissionais da saúde. A seleção destes profissionais é realizada pela Coordenadoria Estadual dos Programas do Governo Federal (PSF e PACS) e segue os seguintes critérios: (a) os candidatos devem ser moradores dos bairros contemplados pelo programa; (b) a escolaridade mínima exigida é o Ensino Fundamental completo; (c) prova escrita sobre situações cotidianas e (d) entrevista.

Seja no trabalho junto à equipe do PSF ou no PACS, os agentes comunitários de saúde fazem a ligação entre as famílias e o serviço de saúde, visitando cada domicílio pelo menos uma vez por mês, realizando o mapeamento de cada área e cadastrando as famílias. Além disso, é papel dos agentes, segundo os programas, estimular a comunidade para práticas que proporcionem melhores (termo que será discutido ao longo deste trabalho) condições de saúde e de vida. As ações, relações e interações destes trabalhado- res com as famílias são construídas a partir de um sistema de idéias ou de um "modo de pensar" otimista ou pessimista sobre as famílias pobres (Yunes \& Szymanski, 2001). Sabendo que estes agentes realizam contatos permanentes, proximais e individualizados junto aos grupos familiares, é importante investigar suas crenças sobre as possibilidades de resiliência em famílias que enfrentam as dificuldades da monoparentalidade somadas à pobreza. Isso poderá orientar a elaboração de programas de atenção, desenvolvimento e educação destas populações.

Com base nas reflexões apresentadas, a primeira etapa deste trabalho buscou conhecer e compreender as percepções e crenças dos agentes comunitários de saúde sobre as possibilidades de resiliência das famílias monoparentais e de baixa renda. Concomitantemente, foram investigados os riscos decorrentes da situação de pobreza e as estratégias de enfrentamento das adversidades de algumas famílias. Objetivou-se, portanto, realizar um paralelo entre as crenças dos agentes sociais e os processos de superação das adversidades que se apresentam nas histórias da convivência familiar, expressos pelas práticas educativas com os filhos, sistemas de crenças, processos de comunicação e organização destas famílias (Walsh, 1998, 2005).

\section{Método}

Qualquer que seja o objeto de estudo, a escolha metodo-lógica é de importância crucial. No que tange à questão da resiliência em famílias de baixa renda, as dificuldades metodológicas são preocupantes e desafiadoras. Sabe-se que o discurso científico sobre o tema é hegemônico e tem por base os estudos estatísticos, em cuja direção se encontra a maioria das pesquisas na área (Yunes \& Szymanski, 2001, 2006). Ao escolher a estratégia metodológica, é importante centrar a atenção àquelas que melhor podem adequar-se à compreensão que o pesquisador deseja obter acerca de um determinado fenômeno. Fazer uma opção metodológica entre quantitativoqualitativo não significa de modo algum desconstruir uma ou outra alternativa, mas sim escolher a abordagem que estará em harmonia com o paradigma que o pesquisador construiu sobre o tema em estudo. Para tratar do tema da resiliência, o pesquisador necessita reconhecer todos os recursos metodológicos que possam favorecer novas descobertas e ampliar o leque de informações sobre o assunto.

Neste caso, concluiu-se que a abordagem qualitativa poderia ampliar o espectro da visão dominante de resiliência com foco no indivíduo, e que as seguintes estratégias metodológicas seriam mais adequadas para se abordar os processos das interações entre agentes e famílias na sua complexidade: as histórias de vida das famílias na modalidade reflexiva, a entrevista reflexiva com os profissionais (Szymanski, 2001) e a grounded-theory (Strauss \& Corbin, 1990).

As histórias de vida na modalidade reflexiva e as entrevistas reflexivas pressupõem dois contatos com o entrevistado e têm por objetivos não só aprofundar a relação entrevistador-entrevistado, mas também possibilitar a 
interação do entrevistado com a análise dos dados propriamente dita. Tal interação ocorre no segundo contato, ocasião em que o entrevistador apresenta a pré-análise da primeira entrevista e o entrevistado pode modificar ou ampliar as categorias apresentadas (Szymanski, 2001).

A grounded-theory, foi cogitada neste caso, por oferecer as possibilidades de organização de grande quantidade de dados qualitativos de forma menos contaminada pelas idéias teóricas e hipóteses que o pesquisador pode apresentar previamente à realização do seu estudo. É uma abordagem particularmente válida para campos de pesquisa pouco conhecidos, o que é perfeitamente compatível com a proposta do estudo em questão. Os passos propostos por essa metodologia de análise permitem a descoberta de "temas que emergem dos próprios dados durante a análise dos textos" (Strauss \& Corbin, 1990). O processo de ler e reler, escrever e reescrever, ouvir e re-ouvir as gravações das entrevistas realizadas com os profissionais propiciou a descoberta dos códigos, a eleição de subcategorias e de categorias e o encontro de suas inter-relações. O detalhamento será apresentado na seção dos resultados.

\section{Participantes}

Para este estudo foram entrevistados quatro agentes comunitários de diferentes bairros de Rio Grande-RS e quatro famílias monoparentais indicadas por estes profissionais. Todos os participantes assinaram um Termo de Consentimento Livre e Esclarecido elaborado de acordo com os artigos da resolução CFP no 16/2000. ${ }^{1}$

$O$ Contato com os Agentes: os quatro agentes comunitários de saúde contatados atuavam em bairros de baixarenda - também conhecidos como vilas (Neiva-Silva, 2003) da cidade. Os trabalhadores relataram em média quatro anos de experiência em atendimento familiar. Dois agentes comunitários de saúde pertenciam ao PACS e dois ao PSF. Três agentes eram do sexo feminino e um era do sexo masculino. De acordo com os relatos, os profissionais se revelaram antigos residentes nos bairros em que atuam, pois moram na região há mais ou menos vinte anos. A maioria tem o ensino médio incompleto e atende aproximadamente 200 famílias de suas respectivas áreas.

As entrevistas com os trabalhadores foram gravadas e continham quatro questões desencadeadoras: (a) Descreve o seu trabalho junto às famílias; (b) Como são as famílias com as quais você trabalha?; (c) Você trabalha com famílias monoparentais? Como elas são?; (d) Dentre essas famílias monoparentais, como são aquelas que para você, "parecem viver bem"? Essas questões estimularam um amplo relato sobre detalhes do trabalho dos agentes comunitários de saúde, bem como trouxeram narrativas sobre as crenças desses profissionais acerca das famílias

${ }^{1} \mathrm{Na}$ ocasião em que este projeto de pesquisa foi equacionado o Comitê de Ética da Fundação Universidade Federal de Rio Grande não estava ainda constituído e por isso a referida proposta não pode ser apreciada. Entretanto, foram respeitadas todas as normas éticas de pesquisa com seres humanos previstas pelo Conselho Nacional de Saúde. residentes nas vilas. Cabe ressaltar, ainda, que no início de cada entrevista foi necessário o esclarecimento dos termos resiliência e monoparentalidade utilizados na pesquisa. Sobre resiliência deu-se a seguinte explicação: "Re-siliência refere-se ao fenômeno que explica os processos que possibilitam pessoas a enfrentarem as crises, traumas e adversidades sem evidências de prejuízos na sua saúde física ou psíquica. Como este fenômeno ainda não está suficientemente explorado no Brasil, estamos conduzindo um estudo sobre esse assunto”. Quanto à expressão "famílias monoparentais" foi dito que são "famílias lideradas por um único adulto - responsável: pai, mãe, avó, etc.” Após a entrevista, cada um dos agentes comunitários de saúde entrevistados indicou uma família monoparental e de baixa-renda que, na sua percepção estaria "enfrentando as adversidades da pobreza e vivendo bem”.

O Contato com as Famílias: Após a indicação e a concordância dos grupos familiares em participarem do estudo, foram realizadas visitas para conhecimento das histórias de vida das famílias. Os dois encontros realizados com cada família foram gravados. O primeiro iniciou com uma questão desencadeadora: "Gostaria de conhecer a história da sua família e peço que vocês me contem da maneira que quiserem”. As famílias contaram suas histórias com poucas interferências do entrevistador, preocupado apenas com a escuta atenta e em propiciar condições para um amplo e detalhado relato. De acordo com os procedimentos da modalidade reflexiva, durante o segundo encontro foram apresentadas as categorias da pré-análise para que as famílias pudessem tecer comentários e interagir com os dados (Szymanski, 2001).

As quatro famílias entrevistadas eram chefiadas por mulheres. As duas primeiras famílias eram compostas por mulheres viúvas que viviam com os filhos e as outras duas tinham como chefe a figura das avós (separadas de seus companheiros) que cuidavam dos filhos e netos.

\section{Resultados}

A seguir serão apresentadas as categorias extraídas a partir das narrativas dos profissionais e das famílias entrevistadas na seguinte seqüência: (a) percepções e crenças dos agentes comunitários de saúde sobre as famílias em situação de pobreza; (b) crenças dos agentes comunitários de saúde sobre as possibilidades de resiliência em famílias monoparentais e de baixa renda; (c) as possibilidades de resiliência que se apresentaram na história de vida das famílias entrevistadas.

\section{Percepções e Crenças dos Agentes Comunitários de Saúde sobre} as Famílias em Situação de Pobreza

A partir das narrativas constatou-se uma variedade de adjetivos que caracterizam as percepções dos agentes comunitários de saúde sobre as famílias com as quais trabalham. Estas atribuições expressam algumas categorias dos pensamentos e concepções dos agentes comunitários de saúde sobre as famílias pobres, conforme demonstra a Figura 1. 


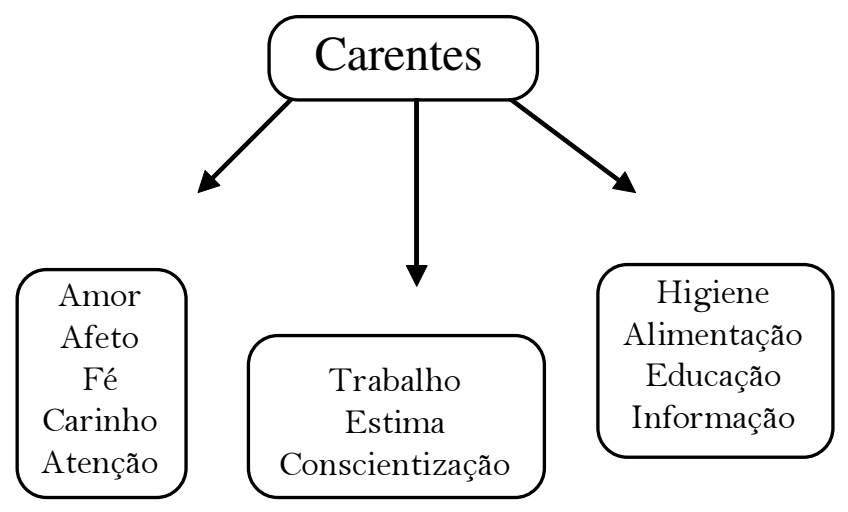

Figura 1. Características das famílias a partir da percepção dos agentes comunitários de saúde.

Portanto, é fato que todos os agentes reconhecem as dificuldades que estas famílias enfrentam. Apesar disso, parece prevalecer uma visão determinista e negativa (pelo número de "nãos" e indicações de "ausências de") com predomínio da percepção da carência, da falta de "alguma coisa". Além disso, os profissionais fazem referências à acomodação das famílias à condição de pobreza, percebida como transmissível de geração para geração. Um dos agentes afirma:

Eles são pobres, eles passam uma vida pobre para os filhos, acham que é normal. Os filhos já estão tendo filhos, que já se criam na mesma. Então é uma corrente, um círculo vicioso que é muito difícil quebrar e sair dele.

Um outro agente enfatiza que algumas famílias são acomodadas e apenas vivem de doações devido à "falta de emprego", o que confere certo reconhecimento das desigualdades de oportunidades e limitações sociais, políticas e econômicas da condição da pobreza. Ele afirma: "Claro tem as exceções: aquelas que vivem de doações, só quando não tem o tal bico”. Outro profissional justifica a acomodação das famílias à condição de miséria responsabilizando o governo pelo assistencialismo prestado às populações de baixa-renda. Assim, esse agente diz: "É culpa do governo que dá demais".

Quando questionados sobre as famílias monoparentais e de baixa renda, os agentes demonstraram a necessidade de um esforço cognitivo para buscar elementos que caracterizassem as famílias que vivem sob essa configuração. A maioria dos discursos trouxe poucas considerações sobre as mesmas e ficava clara a dificuldade desses profissionais em descreverem ou até mesmo "lembrarem" destas famílias: "Agora me pegasse de surpresa. Só olhando mesmo nos cadastros para que eu possa dizer como são essas famílias". Esse dado nos remete a uma retórica reflexão sobre o modelo de família pensado/ idealizado, em oposição aos modelos familiares existentes e vividos na comunidade (Szymanski, 1988). Talvez os agentes comunitários de saúde tenham dificuldade em caracterizar as famílias monoparentais, pois estas não prescrevem o modelo familiar socialmente considerado como "ideal ou correto" - e composto por pai, mãe e filhos. Um dos entrevis- tados caracterizou essas famílias como sendo «diferentes» umas das outras e, segundo ele, não seria possível generalizar os modos de convívio familiar: "são algumas e não são iguais. Cada uma tem uma característica”. Outro agente caracterizou essas famílias em duas classificações: as que trabalham e as que vivem de doações. "Tem essa família que tem um responsável que trabalha ou tem um responsável que vive de doações”. Dois dos agentes comunitários de saúde entrevistados apresentaram suas crenças positivas sobre as famílias em questão: um dos profissionais percebe que a monoparentalidade melhorou a vida das mulheres pela ausência de violência nas relações provocada pela figura masculina e à melhoria das condições financeiras: "agora, essas pessoas que a situação fez elas ficarem monoparentais deixou assim elas até mais felizes”, e outro profissional caracteriza essas famílias como unidas, interessadas, trabalhadoras, amistosas, companheiras e cúmplices na sua relação com os demais membros da família:

Acima de tudo essas aí tu vês até mais força, porque eles brigam, eles correm. Seja a mãe, ou seja o pai, ele consegue ter três, quatro filhos e ir a batalha: vai trabalhar, volta, pega as crianças. Eles são mais interessados.

Crenças dos Agentes Comunitários de Saúde sobre as Possibilidades de Resiliência nas Famílias Monoparentais e de Baixa Renda

Conforme já referido, os agentes comunitários de saúde foram solicitados a indicarem uma família monoparental de sua área de atuação que, na sua percepção, estivesse "vivendo bem". Com isso, foi possível identificar as crenças desses profissionais sobre fatores que contribuem para processos de resiliência nas famílias indicadas. A maioria dos agentes entrevistados enfatizou que as famílias apontadas, apesar da situação de pobreza, sabem administrar "o pouco que têm", no que se refere aos bens materiais e renda familiar. "Não é que vivam na melhor das maravilhas, mas é que ela administra bem aquilo dali . . . Ela mora numa casa boa, bem bonitinha, direitinha, tem banheiro". "Porque toda pessoa precisa saber administrar..., ir adquirindo as coisas aos poucos dentro do possível e arrumando a sua vida aos poucos". Sendo assim, nota-se a valorização das condições financeiras como expressão da superação das dificuldades. Esse dado reforça a crença desses profissionais sobre as possibilidades de resiliência em famílias pobres atrelada à aquisição de bens materiais. Isso pode ser um indicador da secundarização dos fatores interacionais e educacionais da convivência familiar nas concepções dos agentes. Apenas um deles apresentou uma visão diferenciada e apontou a valorização da educação, do trabalho, da iniciativa e da "tranqüilidade" (ausência de brigas e divergências no convívio familiar) no ambiente das famílias monoparentais e de baixa renda:

Elas conseguem se alimentar, elas conseguem se vestir. Agora estão até pensando em construir. De vez em quando têm uma dificuldade e outra, mas elas 
conseguem se virar. E são pessoas assim, pra cima, sabes?! Elas conseguem, vão remando, vão de um jeito, vão de outro e não param, progridem. Viver bem eu acho que entra o lado mental, social, financeiro e tudo.

Esse profissional apresenta crenças sobre resiliência compatíveis com as discussões mais atualizadas sobre o tema. Seu discurso mostrou a importância das pessoas manterem o olhar positivo e a confiança na perspectiva de "melhorar" de vida em vários setores - não só financeiro, apesar das dificuldades.

Possibilidades de Resiliência Identificadas na História de Vida das Famílias Entrevistadas

As histórias de vida das famílias monoparentais e de baixa renda entrevistadas revelaram diferentes situações que constituíram ou constituem riscos à convivência familiar. Entende-se por fatores de risco não apenas os eventos negativos de vida que aumentam a probabilidade de um indivíduo apresentar problemas físicos, sociais ou emocionais, mas os processos dinâmicos das situações de dificuldades que envolvem fatos que antecedem e precedem algumas circunstâncias de vida. $\mathrm{Na}$ seqüência seguem as categorias que emergiram das análises das histórias de vida das famílias investigadas.

O Alcoolismo seguido da violência nas relações apresentaram-se como elementos potenciais de riscos à convivência em duas das famílias entrevistadas. Nestes grupos, após seis ou oito anos de casamento, o marido/pai começou beber e em conseqüência agia violentamente com a família. Tal fato "piorou" a vida familiar, já que a violência física, psicológica e as perdas materiais tornaram-se a tônica das relações familiares conforme os relatos a seguir:

Quando casei foi tudo mais ou menos, aí ele [marido] pegou a beber, aí era um inferno dentro de casa. A bebida é que liquidou com tudo (família 1).

Era uma beleza, [marido] trabalhava junto comigo 'parelhinho'. A gente adquiriu muita coisa. Só que depois de oito anos ele começou a beber e a destruir tudo dentro de casa. Aí quebrava tudo e vendia tudo que tinha dentro de casa. Fiquemos sem nada, nada. Ele 'judiava' muito dos guris e também 'dava' muito (família 2).

Estas perdas materiais e afetivas presentes nas histórias de vida das famílias 1 e 2 mostraram-se associadas à categoria citada anteriormente - alcoolismo e violência nas relações -, em que o marido/pai ao beber sobrecarregava a convivência familiar com gastos abusivos da reduzida renda familiar para o consumo de bebida, além da destruição e venda dos bens materiais.

E depois tudo que ele ganhou, tivemos casa, tivemos tudo. Aí não tinha mais nada, era só beber e jogo de cartas (Família 1).

Cabe destacar que a divisão entre perdas materiais e afetivas é apenas de organização, pois as questões materiais quase sempre se apresentam acopladas às afetivas. Com isso, percebe-se também que perder bens materiais apare- ce em todas as histórias das famílias investigadas, seja por problemas conjugais ligados ao alcoolismo, à violência ou à infidelidade dos parceiros. Assim, a terceira família relatou, além das diversas perdas materiais, a ênfase no luto pela morte de parentes e do primeiro filho recém nascido. Quanto ao aspecto material, as perdas referiram-se à casa, aos poucos bens (o marido vendeu pertences sem que a esposa soubesse) e aos materiais de construção roubados logo no início da obra da atual casa. "Eu vim pra cuidar meu pai em Rio Grande, quando voltei pra Porto Alegre não encontrei nem ele [marido] nem minhas coisas". (família 3). "Porque ele tinha vendido a casa sem avisar ela. Foi um baque muito grande, já tinha sofrido um baque por ter perdido o meu pai” - interferiu a filha dessa família. As marcantes perdas afetivas foram aspectos também presentes na história de vida da família 4, como a morte de dois filhos recém nascidos e da mãe. Quanto ao aspecto material foi relatado o episódio da casa que o marido passou para o filho, que por sua vez retirou dela. "Ele [filho] me roubou tudo, outro ladrão... E no fim se tornou tudo bandido”.

Com relação à categoria infidelidade, esta também esteve presente nas histórias de vida das famílias 3 e 4. Nestes casos, a infidelidade dos maridos culminou com a separação dos casais. Com isso, as mulheres tornaramse as lideranças das famílias, responsáveis pelo cuidado e educação dos filhos, sem apoio do marido. Ele [marido] tinha relações extraconjugais ... "Ele já tinha outra pessoa e eu não sabia. Ele vendeu tudo pra morar com outra pessoa" (família 3). "Ele andava aí com essas 'vagabundas"” (família 4).

Uma situação de risco evidenciada em todas as famílias investigadas decorre da própria condição de miserabilidade, que traz para a vida destas famílias a privação financeira $e$ sócio-cultural (Garbarino \& Abramovitz, 1992). Embora a pobreza não seja a causa direta dos problemas evidenciados na convivência das famílias de baixa renda, as circunstâncias associadas a ela apresentam alta relação com as adversidades enfrentadas por esta população (Yunes, 2001a). Os relatos que seguem expressam algumas situações:

Agora mesmo to sem trabalhar, daí eu e ela [filha] só com uma pensão não dá, e tem isso aí também né, a gente quer arrumar as coisas dentro de casa e não ter o dinheiro e com criança pequena não é fácil, ainda bem que ele tem saúde (família 3).

Três horas da madrugada botei o meu guri em cima de uma carroça e nós fomo para o hospital. Ele numa charrete e pedindo: - não sai correndo com o cavalo, mano, se não eu não agüiento de dor (família 2);

Eu não tinha casa eu morava junto com os porcos (família 2).

A constatação das situações de dificuldades relatadas nas histórias de vida das famílias estudadas torna possível identificar indicadores de superação das dificuldades. Estes elementos representados pelas crenças das famílias podem ser categorizados como fatores/processos de proteção (Rutter, 1985), ou influências que modificam, melhoram 
ou alteram respostas pessoais para determinados riscos de desadaptação ou adoecimento.

As categorias estudo e trabalho apresentaram-se nos discursos como fatores que contribuem ou que podem contribuir para o enfrentamento das adversidades. A categoria trabalho apresentou diferentes sentidos nas histórias de vida das famílias investigadas. Na família 1, o trabalho mostrou-se presente em todos os momentos da vida das pessoas, desde a infância. A mulher conta que teve que trabalhar desde os oito anos de idade, cuidando a casa e os irmãos para que a mãe e o pai pudessem trabalhar. "Eu tive um mês na escola e a minha mãe me tirou pra mim cuidar a minha irmã. Eu fazia comida pra doze, treze pessoas com oito anos". Depois, teve que trabalhar com o marido e, muitas vezes, substituí-lo. Atualmente ajuda no sustento da casa e relata que seus filhos vêm trabalhando com ela desde pequenos (seis anos de idade). Apesar das condições de risco impostas pelo trabalho desde a infância e das considerações críticas sobre as conseqüências do trabalho infantil em prejuízo ao desenvolvimento humano, percebe-se que os membros desta família mostram-se orgulhosos de ter, ao longo de toda a sua história de vida, enfrentado a pobreza através do trabalho e da união/ ajuda mútua entre mãe e filhos. O fato de não se acomodarem ou dependerem da solidariedade de outros para a sua sobrevivência através do exercício do trabalho qualifica o conceito que a família tem deles mesmos. Na família 2 , a líder da família demonstra orgulho por ter filhos trabalhadores que sustentam a família e que não permitem que ela trabalhe.

Depois que aconteceu isso com ele [morte do marido], os guris me ajudavam, estavam sempre trabalhando, o mais velho e esse [filho] trabalhando estavam sempre me ajudando. Eles me dizem: - Não mãe, enquanto a gente tiver do teu lado, a gente vai sempre te ajudar, muito ou pouco a gente sempre te dá.

A mulher e a filha da família 3 enfocaram a categoria trabalho através do relato dos problemas de saúde física do marido/pai com os empregos alegando que ele "não gostava de trabalhar... e ele ficava dormindo dentro de casa... vivia sempre doente do bronquite”. Na família 4, a mulher demonstrou a concepção de que o trabalho autônomo é melhor do que o empregatício e justifica sua posição pela educação recebida de sua mãe. Diz que transmitiu esta concepção para seus filhos e afirma: "não ia ser pinico de ninguém”. Paradoxalmente, seu discurso sobre trabalho expressa uma questão de gênero conservadora sobre o papel feminino e percebe as mulheres ocupando um lugar social na casa: "a minha mãe fazia a lida, costurava, fazia tudo que quisessem, mas nunca trabalhou, graças a Deus nunca trabalhou fora".

O sentido positivo do trabalho atribuído pelas famílias investigadas se relaciona com o que Sarti (1996) aponta como o valor do trabalho no sistema moral dos pobres. A autora aponta que a moral do trabalho se entrelaça com o sistema moral da família. O trabalho, nesse sentido, serve como afirmação pessoal e social positiva diante das desigualdades e envolve todos os membros da família através de obrigações mútuas. Portanto, o trabalho é percebido como um compromisso moral num sistema relacional de ajuda e troca dentro da família. Estas obrigações mútuas permitem cumprir que: "aos pais cabe dar casa e comida" (p. 80) e "ao jovem dar, se não inteiro, pelo menos uma parte dos seus rendimentos à mãe para cobrir os gastos da família" (p. 72) como forma de retribuição e "troca moral".

Com relação ao estudo, apesar das líderes das famílias possuírem baixa escolaridade, a maior parte reconhece o valor dos estudos na vida dos filhos.

Depois que eu fiquei sozinha é que eu vim pra cá pros meus guris estudar . . . eu nunca tive no colégio. Aí eu vim embora, assim que ele [filho] completou a oitava série. O outro já terminou o segundo grau. (família 1).

Nas famílias 1 e 3, as chefes de família demonstram orgulho dos filhos que freqüentam a escola e são estudiosos. "Ela [filha] tem segundo grau e tudo, só não consegue é serviço, tá difícil mesmo” (família 3). Já as famílias 2 e 4, apesar de expressarem a valorização dos estudos, apontam que no período do casamento, os maridos não deixavam os filhos estudarem, por motivo de ciúme/ posse ou por dificuldades financeiras: "Todos eles foram para o colégio, mas o pai..." "Ele [pai] não deixava, pra não gastar" (filho da família 4).

Sarti (1996) também evidencia o valor positivo atribuído à educação nas famílias pobres. Esta categoria é percebida como uma "marca de distinção e de superioridade" da população pobre diante das desigualdades sociais, pois "uma família cujos filhos não freqüentam escola é vista como socialmente inferior” (p. 81).

Outra categoria identificada como protetora nas situações de crise das vidas das famílias investigadas é o olhar positivo para perspectivas de um futuro melhor, ou seja, o desejo de melhoria das condições materiais e a visualização da prosperidade. No entanto, pode-se observar por alguns relatos, que as chefes de famílias da maioria dos grupos pesquisados apresentam perspectivas de futuro restritas apenas aos filhos e netos. Para algumas famílias (2 e 3), a análise de tal categoria permitiu verificar que sua busca por melhores condições de vida passa pela reivindicação dos direitos na justiça, o que mostra clareza de informações e o exercício de cidadania nestes grupos familiares:

Ele [marido] me ameaçava é de me matar. Fui fazer uma denúncia. ... Que qualquer coisa que acontece comigo já tá registrado (família 2).

Invadiram meu terreno, a entrada do portão era maior. E quando eu cheguei já tava o muro quase dentro do meu pátio. Aí eu 'rodei a baiana' e botei na justiça. Inclusive tão arrumando (família 3).

Um outro indicador de proteção presente na vida das famílias investigadas refere-se às possibilidades de obter ajuda de outros, através da mobilização da família extensa ou de outras pessoas significativas eleitas como apoio afetivo $e$ instrumental. A líder da família 1 afirma que conseguiu superar as dificuldades sem ajuda. Porém, a análise da entrevista revela a contradição dessa premissa por ocasião 
do relato da morte do marido. Ela conta que teve a ajuda dos parentes, da vizinha que emprestou a casa onde reside e dos filhos que sempre a ajudaram no sustento. Na família 2 , a mulher admite receber ajuda dos filhos, do tio que doou a casa e que até hoje a auxilia quase que mensalmente no sustento, além da vizinha e da agente comunitária de saúde. E nas famílias 3 e 4, também se notou a presença de ajuda financeira e afetiva de parentes próximos recebidas em momentos de maiores necessidades.

Identificou-se ainda que a coesão familiar é um dos fatores que contribui para amenizar o peso das adversidades. A maioria das famílias enfatiza a união dos membros da família como um importante elemento da dinâmica familiar:

"Os filhos não me incomodam, graças a Deus. Quando trabalham me ajudam. Quando não trabalham a gente vive como pode. Uns ajudavam os outros, sozinho ninguém fazia nada". (família 1); "Ter meus filhos junto comigo com saúde, isso é que é o mais importante pra mim: eles junto comigo" (família 2); "Eles sempre na volta. Sempre na minha volta. Nem eu soltava no meu campo. A minha mãe me ensinou assim. A gente tá sempre de olho" (família 4). De acordo com alguns autores, (Walsh, 1998, 2005; Yunes, 2001a) as famílias vivem melhor quando seus membros se sentem unidos, envolvidos emocionalmente e comprometidos uns com os outros.

\section{Discussão e Considerações Finais}

Muitas das categorias apresentadas acima podem ser relacionadas ao que Walsh $(1998,2003,2005)$ apresenta como processos-chave da resiliência em famílias. A autora fundamenta o seu modelo teórico denominado "funcionamento familiar efetivo" a partir de um panorama conceitual com três domínios: sistema de crenças da família (o coração e alma da resiliência), padrões de organização e processos de comunicação. Estes processos-chave não podem ser considerados pressupostos fixos para a definição da resiliência familiar, pois o fenômeno apresenta-se de diferentes formas e possibilidades a depender de cada contexto familiar e sua inserção cultural e histórica. Contudo, os processos-chave da resiliência em famílias apontados por Walsh $(1998,2003,2005)$ são elementos importantes para orientar a interpretação das categorias surgidas nesta investigação.

As categorias identificadas nas análises das histórias de vida das famílias pobres e monoparentais trazem a presença de vários elementos de resiliência, tais como: olhar positivo e coragem para romper com velhos padrões, a coesão do grupo, o sentido atribuído ao estudo e ao trabalho, a comunicação clara entre os membros, a flexibilidade na organização das rotinas, a presença de figuras de apoio na família extensa, a perspectiva positiva de futuro, a busca de qualidade de vida mais digna através da reivindicação dos direitos e cumprimento dos seus deveres e compromissos perante a sociedade. Claramente, tais elementos se contrapõem às crenças pessimistas dos profissionais, neste caso, os agentes comunitários de saúde que se demonstraram reticentes quanto às possibilidades de superação das adversidades advindas da pobreza nestas populações.

Sendo assim, alguns dos aspectos descritos pelos agentes de saúde como ausentes na convivência das famílias pobres são expressos como valorizados e presentes nas histórias de vida narradas pelas famílias monoparentais e de baixa renda investigadas. Assim, por exemplo, as seguintes afirmações dos agentes sobre as características das famílias com as quais trabalham: "As crianças não valorizam os estudos", "As pessoas são desinteressadas, acomodadas e preguiçosas", opõe-se a "valorização do estudo e/ou do trabalho", fatores esses que podem ser alguns importantes indicativos de proteção e resiliência nas famílias entrevistadas.

Com isso, notou-se que as famílias pobres que compõem o cotidiano do trabalho dos agentes comunitários de saúde entrevistados são percebidas através de adjetivos que sublinham a vulnerabilidade e fragilidade da dinâmica familiar. As percepções otimistas de melhoria de vida e de superação das dificuldades ficam pouco salientes ou não são sequer mencionadas por esses profissionais. É relevante citar que os agentes sociais reconhecem que as famílias vivenciam uma diversidade de dificuldades e de condições de risco: experiência de fome, baixa escolaridade, analfabetismo, diferentes formas de violência, falta de segurança, instabilidade econômica, poucas oportunidades de emprego. Entretanto, deve-se ressaltar que estes e outros fatores, como também os mecanismos abstratos, invisíveis e implícitos de exclusão social, são advindos da extrema miséria, do desemprego e da carência de condições de moradia e recursos básicos necessários para a sobrevivência digna. Isso tudo está muito distante do alcance ou controle dessas populações. Na maioria das entrevistas, este olhar macrossistêmico (Bronfenbrenner, 1979/1996) sobre a pobreza e as dificuldades enfrentadas pelas famílias não se faz presente na descritiva dos profissionais.

Para estabelecer uma relação empática, genuína e geradora do desenvolvimento da identidade positiva e da consciência transformadora nestes grupos familiares, os agentes sociais deveriam reconhecer as reais dificuldades vivenciadas histórica e socialmente por estas famílias ao longo de gerações vivendo na pobreza. Ao contrário, as atitudes pessimistas e o descrédito dos profissionais em relação às famílias, podem agir em prejuízo do atendimento dispensado a essas populações. Assim, ao invés de contribuir para uma conscientização e mudança de situações de risco vivenciadas por essas famílias, as crenças desses profissionais resul tam numa atuação pouco eficiente e apática, norteada por um sistema de idéias que culpabiliza as famílias pela pobreza e as impossibilita de visualizar soluções (Vasconcelos, Yunes \& Garcia, 2006).

Por fim, cabe ressaltar que nesta pesquisa realizada com as famílias monoparentais e de baixa renda não se buscou comparar as histórias de vida ou as categorias que emergiram na análise dos discursos, mas sim compreender o dinamismo da vivência de cada grupo familiar. É fato que alguns dos fatores de risco e/ou fatores de proteção identificados nesse estudo foram semelhantes entre todas as 
famílias. No entanto, é importante marcar que cada família deve ser percebida como uma pequena sociedade com características próprias e que cada grupo familiar pode apresentar mecanismos e processos diferenciados de superação das adversidades (Garbarino \& Abramowitz, 1992).

Nesse sentido, a investigação acerca das possibilidades de resiliência em famílias cujas trajetórias de vida apontam adversidades como a monoparentalidade e a pobreza é relevante, não apenas para auxiliar no entendimento das complexidades das relações familiares, mas também por apontar a urgência na (re) formulação e (re) construção de programas públicos de educação que visem a auxiliar a (re) elaboração de visões dos agentes sociais e suas práticas educativas fatalistas, deterministas e pessimistas. Suas interações com as famílias necessitam pautar-se em sentimentos mútuos de confiança, empatia e reciprocidade. Só assim o cuidado e a educação poderão efetivamente ser os propulsores do bem estar destas populações.

\section{Referências}

Antonovsky, A., \& Sourani, T. (1988). Family sense of coherence and family sense of adaptation. Journal of Marriage and the Family, 50, 79-92.

Bronfenbrenner, U. (1996). A ecologia do desenvolvimento humano: Experimentos naturais e planejados. Porto Alegre, RS: Artes Médicas. (Original publicado em 1979)

Carvalho, M. C. B. (1995). A priorização da família na agenda da política social. In M. C.B. Carvalho (Ed.), A família contemporânea em debate. São Paulo, SP: EDUC.

Cecconello, A. M. (2003). Resiliência e vulnerabilidade em famílias em situação de risco. Tese de Doutorado não-publicada, Curso de Pós-Graduação em Psicologia do Desenvolvimento, Universidade federal do Rio Grande do Sul, Porto Alegre, RS.

De Antoni, C., \& Koller, S. H. (2000). Vulnerabilidade e resiliência familiar: Um estudo com adolescentes que sofreram maus tratos intrafamiliares. Psico, 31(1), 39-66.

Garbarino, J., \& Abramowitz, R. H. (1992). Sociocultural risk and opportunity. In J. Garbarino. Children and families in the social environment (2. ed.). New York: Aldine de Gruyter.

Garcia, N. M., \& Yunes, M. A. M. (2006). Resiliência familiar: Baixa renda e monoparentalidade. In D. D. Dell'Aglio, S.H. Koller \& M. A .M. Yunes (Eds.), Resiliência e psicologia positiva: Interfaces do risco à proteção (pp. 117-140). São Paulo, SP Casa do Psicólogo.

Instituto Brasileiro de Geografia e Estatística. (2000). Censo demográfico 2000. Brasília, DF: IBGE. Retirado de http:// www.ibge.gov.br

Lindblad-Goldberg, M. (1989). Successful minority single-parent families. In L. Combrink-Graham. Children in family contexts (pp. 116-134). New York: Guilford Press.

Luthar, S. S., \& Zigler, E. (1991). Vulnerability and competence: A review of research on resilience in childhood. American Journal of Orthopsychiatry, 61(1), 6-22.

McCubbin, H. I., Thompson, E. A., Thompson, A. I., \& Futrell, J. A. (1999). The dynamics of resilient families. Thousand Oaks, CA: Sage.

Madanes, C. (1984). Behind the one way mirror: Advances in the practice of strategic therapy. San Francisco, CA: Jossey- Bass.
Martineau, S. (1999). Rewriting resilience: A critical discourse analysis of childhood resilience and the politics of teaching resilience to «kids at risk». Tese de Doutorado não-publicada, University of British Columbia, Vancouver, Canada.

Masten, A. S. (2001). Ordinary magic: Resilience processes in development. American Psychologist, 56(3), 227-238.

Masten, A. S., \& Garmezy, N. (1985). Risk, vulnerability and protective factors in developmental psychopathology. In B. B. Lahey \& A. E. Kazdin. Advances in clinical child psychology (Vol. 8, pp. 1-52). New York: Plenum Press.

Mello, S. L. (1995). Família: Perspectiva teórica e observação factual. In M. do C. B. Carvalho (Ed.), A família contemporânea em debate (pp. 51-60). São Paulo, SP: EDUC.

Ministério da Saúde. (2001). Programa de Agentes Comunitários de Saúde. Programa Saúde da Família. Brasília, DF: Autor. Retirado de http://dtr2001.saúde.gov.br/psf/programa/ index.asp

Neiva-Silva, L. (2003). Expectativas futuras de adolescentes em situação de rua: Um estudo autofotográfico. Dissertação de Mestrado não-publicada, Curso de Pós-Graduação em Psicologia do Desenvolvimento, Universidade Federal do Rio Grande do Sul, Porto Alegre, RS.

Rutter, M. (1985). Resilience in the face of adversity: Protective factors and resistance to psychiatric disorder. British Journal of Psychiatry, 147, 598-611.

Rutter, M. (1993). Resilience: Some conceptual considerations. Journal of Adolescent Health,_14, 626-631.

Sarti, C. A. (1996). A família como espelho: Um estudo sobre a moral dos pobres. Campinas, SP: Autores Associados.

Szymanski, H. R. (1988). Um estudo sobre o significado de família. Tese de Doutorado não-publicada, Programa de Pós-Graduação em Educação: Psicologia da Educação, Pontifícia Universidade Católica de São Paulo, SP.

Szymanski, H. (2001). A entrevista reflexiva. Revista Psicologia da Educação, 10/11, 193-215.

Sonn, C. C., \& Fisher, A. T. (1998). Sense of community: Community resilient responses to oppression and change. Journal of Community Psychology, 26(5), 457-472.

Strauss, A., \& Corbin, J. (1990). Basics of qualitative research: Grounded theory procedures and techniques. London: Sage.

Trombeta, L. H. A. P., \& Guzzo, R. S. (2002). Enfrentando o cotidiano adverso: Estudo sobre resiliência em adolescentes. Campinas, SP: Alínea.

Vasconcelos, Q. A., Yunes, M. A. M., \& Garcia, N. M. (2006). Crianças e adolescentes institucionalizados: Um estudo ecológico sobre as relações entre a família e a instituição de abrigo. Trabalho apresentado no VI ANPEd Sul: Pós-Graduação em Educação no Brasil: Novas Questões? Santa Maria, RS.

Walsh, F. (1996). The concept of family resilience: crisis and challenge. Family Process, 35, 26 1-281.

Walsh, F. (1998). Strengthening family resilience. New York, London: The Guilford Press.

Walsh, F. (2003). Family resilience: Framework for clinical practice. Family Process, 42(1), 1-18.

Walsh, F. (2005). Fortalecendo a resiliência familiar. São Paulo, SP: Roca.

Werner, E. E., \& Smith, R. S. (1992). Overcoming the odds: Highrisk children from birth to adulthood. London: Cornell University Press.

Yunes, M. A. M. (2001a). A aplicação da «grounded-theory» como método de análise qualitativa no estudo da resiliência em famílias de baixa renda. Revista do Departamento de Psicologia da UFF, 13(2), 123-138. 
Yunes, M. A. M., Garcia, N. M. \& Albuquerque, B. de M. (2007). Monoparentalidade, Pobreza e Resiliência: Entre as Crenças dos Profissionais e as Possibilidades da Convivência Familiar.

Yunes, M. A. M. (2001b). A questão triplamente controvertida da resiliência em famílias de baixa renda. Tese de Doutorado nãopublicada, Programa de Pós-Graduação em Educação: Psicologia da Educação, Pontifícia Universidade Católica de São Paulo, SP.

Yunes, M. A. M. (2003). Psicologia positiva e resiliência: O foco no indivíduo e na família [Edição especial]. Psicologia em Estudo, 8, 75-84

Yunes, M. A. M. (2006a). Os discursos sobre a questão da resiliência: Expressões e consequiências para a promoção do desenvolvimento saudável. In D. Colinvaux, L.B. Leite \& D. D. Dell'Aglio (Eds.), Psicologia do Desenvolvimento: Teorias, pesquisas e aplicações (pp. 225-246). São Paulo, SP: Casa do Psicólogo.

Yunes, M. A. M. (2006b). Psicologia positiva e resiliência: Foco no indivíduo e na família. In D. D. Dell'Aglio, S. H. Koller \& M. A. M. Yunes (Eds.), Resiliência e psicologia positiva: Interfaces do risco à proteção (pp. 45-68). São Paulo, SP: Casa do Psicólogo.

Yunes, M. A. M., \& Szymanski, H. (2001). Resiliência: Noção, conceitos afins e considerações críticas. In J. Tavares (Ed.), Resiliência e Educação (pp. 13-42). São Paulo, SP: Cortez.

Yunes, M. A. M., \& Szymanski, H. (2006). O estudo de uma família que supera as adversidades da pobreza: Um caso de resiliência em família. Psicodebate: Psicologia, Culturay Sociedad, 7, 119-139. 